\section{Processos fonológicos por substituição ou transformação na fala de amapaenses: uma abordagem geossociolinguística}

Phonological processes for substitution or transformation in Amapá speech: a geossociolinguística approach

Romário Duarte SANCHES (UEAP) romario.sanches@ueap.edu.br

Michele Silva de CARVALHO (UNIFAP) michelecarvalho.ap@gmail.com

Recebido em: 22 de jan. de 2020. Aceito em: 24 de mar. de 2020.
SANCHES, Romário Duarte; CARVALHO, Michele Silva de. Processos fonológicos por substituição ou transformação na fala de amapaenses: uma abordagem geossociolinguística. Entrepalavras, Fortaleza, v. 10, n. 2, e1816, p. 1-23, maio-ago/2020. DOI: 10.22168/22376321-21816.

Resumo: O artigo tem por objetivo identificar os processos fonológicos de substituição ou transformação presentes no falar amapaense a partir do banco de dados do projeto Atlas Linguístico do Amapá (ALAP). A descrição foi feita com base nos postulados da Geossociolinguística (RAZKY, 2010), que une os pressupostos metodológicos da Sociolinguística com os da Geolinguística. A metodologia empregada corresponde aos parâmetros adotados pelo projeto ALAP, com a seleção de 10 localidades do estado do Amapá, onde foram entrevistados 40 informantes. Os itens fonéticos analisados nesta pesquisa foram: assobio, passagem, homem, arroz, três, giz, caspa, paz, prateleira, caixa, tesoura, manteiga, ouvido, peixe, elefante, hóspede e muito. Os resultados mostram a presença dos seguintes processos fonológicos: degeneração, desnasalação, ditongação, monotongação, metafonia e nasalação. Os fatores geográficos idade e sexo condicionam a presença de certos processos fonológicos no falar amapaense.

Palavras-chave: Geolinguística. Sociolinguística. Geossociolinguística. 
V. $10(2)$

$1-23$

maio-ago

2020

Abstract: The article aims to identify the phonological processes of substitution or transformation present in Amapá speaking from the database of the Atlas Linguistic Project of Amapá (ALAP). The description was made based on the postulates of Geossociolinguistics (RAZKY, 2010) that unites the methodological assumptions of Sociolinguistics with those of Geolinguistics. The methodology used corresponds to the parameters adopted by the ALAP project, with the selection of 10 locations in the state of Amapá, where 40 informants were interviewed. The phonetic items analyzed in this research were: assobio, passagem, homem, arroz, três, giz, caspa, paz, prateleira, caixa, tesoura, manteiga, ouvido, peixe, elefante, hóspede and muito. The results show the presence of the following phonological phenomena: degeneration, desnasalation, diphthongation, monotongation, metaphony and nasalation. Extralinguistic factors condition the presence of certain phonological phenomena in Amapá speech.

Keywords: Geolinguistics. Sociolinguistics. Geossociolinguistics.

\section{Introdução}

No Brasil, os estudos nas áreas da Dialetologia e da Geolinguística começaram a surgir na metade do século XX, impulsionados pelas primeiras publicações de atlas linguísticos regionais. Entretanto, ganharam força com a proposta metodológica do projeto Atlas Linguístico do Brasil (ALiB), em 1996. Pode-se dizer que, a partir de então, inúmeros estudos variacionistas sobre o português brasileiro (doravante $\mathrm{PB}$ ) foram e continuam sendo realizados em diferentes regiões do país.

A Dialetologia, entendida como ciência geral da variação, tem como método a Geolinguística que busca descrever e mapear os usos linguísticos realizados em diferentes espaços geossociais. Para isso, os estudos dialetológicos e geolinguísticos, em sua maioria, são feitos com base na pesquisa de campo, no tratamento de dados linguísticos e na descrição minuciosa dos resultados.

Desta forma, este trabalho tem como objetivo identificar os processos fonológicos de substituição ou transformação presentes no falar amapaense a partir do banco de dados do projeto Atlas Linguístico do Amapá (ALAP). A pesquisa justifica-se pela carência de estudos linguísticos sobre o português falado no Amapá, tendo em vista que somente na última década pode-se apreciar uma centena de pesquisas publicadas sobre variação linguística (fonética e lexical) no estado. O artigo está dividido em cinco seções: introdução, discussão teórica, metodologia, apresentação dos resultados e conclusão. 


\section{Sociolinguística, Dialetologia e Geossociolinguística}

Este artigo tem como suporte teórico as discussões concernentes ao escopo da Sociolinguística, da Dialetologia e da Geossociolinguística. Neste sentido, cabe pontuar brevemente o que estuda cada uma delas.

Segundo Mollica e Braga (2017, p. 09), a Sociolinguística visa estudar "a língua em uso no seio das comunidades de fala, voltando a atenção para um tipo de investigação que correlaciona aspectos linguísticos e sociais". É tratada como uma disciplina que visa mostrar o uso da língua e sua influência interna e externa; e tem como áreas de interesse o aparecimento e a extinção de línguas nativas; a variação e a mudança linguística; além do contato entre diferentes línguas, que resulta em fenômenos como o multilinguismo ou bilinguismo.

A Sociolinguística possui como correntes de estudos a Sociolinguística Variacionista e Sociolinguística Interacionista. Aqui, cabe mencionar a primeira que também é conhecida como: Sociolinguística Laboviana, Sociolinguística Quantitativa ou Teoria da Variação.

A Sociolinguística Variacionista trata de um modelo teóricometodológico voltado para a análise das variações linguísticas, operando com números e tratamento estatístico dos dados, levando em consideração a seguinte estratificação social: idade, gênero, profissão, classe social, dentre outras. Dessa forma, busca-se o alinhamento entre a língua e sociedade, buscando explicar a realização de variantes linguísticas condicionadas por fatores internos (semânticas, sintáticas, morfológicas, fonético-fonológicas) e externos à língua (diferença de classe social, sexo, escolaridade, idade, região, nível de escolaridade).

Outra área do conhecimento que se ocupa de estudos voltados para as variações da língua é a Dialetologia que faz uso da descrição das variedades linguísticas com base no espaço geográfico. "A dialetologia é tratada como uma ciência que brotou nos fins do século XIXe que demonstra, até os dias de hoje, um maior interesse pelos dialetos regionais, rurais e sua distribuição e intercomparação" (FERREIRA; CARDOSO, 1994, p. 18).

Ressalta-se ainda que, numa perspectiva mais atual, a Dialetologia passa a ser vista como "um ramo dos estudos linguísticos que assume a tarefa de identificar, descrever e situar os diferentes usos em que uma língua se diversifica, conforme a sua distribuição espacial, sociocultural e cronológica" (CARDOSO, 2010, p. 15). 
V. $10(2)$

$1-23$

maio-ago

2020

Assim, tanto a Sociolinguística como a Dialetologia tem o mesmo objeto de estudo, a variação dos usos da língua. Entretanto, apesar de parecidas por conta da abordagem variacionista, elas diferem-se da seguinte forma: a Sociolinguística "centra-se na correlação entre os fatos linguísticos e os fatores sociais, priorizando, dessa forma, as relações sociolinguísticas". E a Dialetologia, que também considera os fatores sociais em seu estudo, "tem como base da sua descrição a localização espacial dos fatos considerados, configurando-se, dessa forma, como eminentemente diatópica" (CARDOSO, 2010, p. 26).

Dentro da Dialetologia, encontra-se o método da Geografia Linguística ou Geolinguística. Este foi criado pelos dialetólogos, de acordo com Guedes (2012, p. 25), com a intenção de registrar e comparar os resultados das pesquisas linguísticas em localidades diferentes através da técnica da cartografia linguística.

Sobre a relação entre Dialetologia e Geolinguística, Aragão (2009, p. 71 apud GUEDES, 2012, p. 25) afirma que a dialetologia de hoje não é uma mera geografia linguística, como era considerada antes, em que se focalizavam as variações regionais ou diatópicas, apresentando resultados monodimensionais, monostráticos, monogeracionais e monofásicos. Atualmente, como afirma Cardoso (2010), a dialetologia moderna ampliou o seu campo de observação, e hoje considera variáveis sociais mais complexas como: diageracional, diagenérica, diassexual, diastrática e diafásica.

Essa ampliação da análise da variação linguística favoreceu o surgimento de novas vertentes dentro do escopo da Dialetologia, cita-se a Geossociolinguística apresentada por Razky (2010) como um modelo variacionista que busca unir o aparato metodológico da Sociolinguística com o da Geolinguística, compensando os aspectos sociais isentos na abordagem da geolinguística tradicional.

De acordo com Sanches (2019, p. 21), a Geossociolinguística busca controlar o aspecto geográfico e social da variação linguística. Em relação ao primeiro aspecto, o foco está na caracterização de áreas dialetais ou agrupamentos lexicais ${ }^{1}$; e, o segundo se concentra nas influências de variáveis sociais (como idade, sexo e nível de escolaridade) e nas escolhas linguísticas dos falantes.

${ }^{1}$ Coexistência de variantes lexicais em uma mesma demarcação territorial (RAZKY, 2013). 


\section{Processos Fonológicos}

O conceito de processos fonológicos foi formulado primeiramente por David Stampe, em 1973. Desde então, esse conceito já foi revisto e ampliado por outros pesquisadores. Para Stampe (1973 apud OTHERO, 2005), o processo fonológico é tratado como uma operação mental que se aplica à fala para substituir, no lugar de uma classe de sons ou de uma sequência de sons que apresentam uma dificuldade específica na fala do indivíduo. Em suma, pode-se dizer que os processos fonológicos são alterações de fones ou de fonemas de uma língua natural.

Yavas, Hernandorena e Lamprecht (1991 apud OTHERO, 2005) afirmam que os processos fonológicos são naturais e inatos, pois derivam das necessidades e dificuldades articulatórias e perceptuais do ser humano, resultando em adaptações dos padrões da fala às restrições naturais da capacidade humana, tanto na produção como na percepção. Para eles, os processos são considerados inatos:

[...] porque são limitações com as quais a criança nasce e que ela tem que superar na medida em que não façam parte do sistema de sua língua materna. Por serem inatos ao ser humano, os processos fonológicos são universais, isto é, encontrados em todas as crianças. (YAVAS; HERNANDORENA; LAMPRECHT, 1991, p. 91).

Segundo Othero (2005), foram muitos os estudos feitos com base nos processos fonológicos propostos por Stampe (1973). Vale ressaltar que dentre esses estudos não há um consenso sobre o número total de processos fonológicos que podem ocorrer dentro do sistema linguístico. Para Yavas, Hernandorena e Lamprecht (1991), o número de processos pode variar de 08 a 42.

No que tange aos processos fonológicos do português brasileiro, Silva (2011) aponta, conforme os estudos de Bisol (2005) e Lamprecht (2004), para quatro tipos: processos de apagamento; processos de adição; processos de transposição; e processos de substituição. Esses processos podem resultar em fenômenos fonológicos específicos. Por exemplo, no processo fonológico de apagamento, quando há supressão de um segmento na articulação de um vocábulo, enquadram-se os fenômenos: aférese, síncope, apócope e haplologia.

No processo fonológico de adição, quando há a inserção de consoantes, de vogais ou de glides num vocábulo, acomodam-se os 
V. $10(2)$

$1-23$

maio-ago

2020

fenômenos: prótese, epêntese e paragoge. Já no processo fonológico de transposição, quando um segmento troca de posição dentro de um mesmo vocábulo, encaixam-se os fenômenos: comutação, permutação, deslocamento, metátese, hipértese, sístole e diástole.

Por último, no processo fonológico de substituição ou transformação, quando um fonema de um vocábulo se transforma, passando a ser outro fonema distinto em lugar do primeiro, inserem-se os fenômenos: degeneração, desnasalação, dissimilação, assimilação, palatalização, despalatalização ou iotização, africativização, retroflexão, sonorização (ou abrandamento), dessonorização, metafonia, juntura intervocabular ou sândi, labialização, decaimento, yeísmo, rotacismo, lambdacismo, ditongação, monotongação e nasalação.

Para este trabalho, cabe ressaltar os seguintes fenômenos fonológicos de substituição ou transformação: degeneração, desnasalação, ditongação, monotongação, metafonia e nasalação. A seguir apresenta-se o quadro 01 explicitando os referidos fenômenos.

Quadro 01 - Processos fonológicos de substituição ou transformação

a) degeneração: troca do fonema /b/ pelo fonema /v/: assobiar > assoviar (forma registrada).

b) desnasalação: transformação de um fonema nasal a um fonema oral: virgem >virge.

Fenômenos

c) ditongação: transformação de uma vogal ou um hiato em ditongo:

fonológicos caranguejo >carangueijo.

d) monotongação: transformação ou redução de um ditongo em uma vogal: manteiga > mantega

e) metafonia: alteração do timbre ou da altura de uma vogal: cadê >quedê (forma registrada).

f) nasalação: troca de um fonema oral a um fonema nasal: até >inté. Fonte: Dados de Botelho e Leite (2005, p. 6-8) (Adaptado pelos autores).

Os processos fonológicos expostos acima serão retomados posteriormente, na seção que trata da apresentação dos resultados, com base em dados sonoros de fala de amapaenses. A seguir apresenta-se a metodologia adotada para a pesquisa.

\section{Metodologia}

Este estudo tem como suporte metodológico a geolinguística, de caráter geossociolinguístico, tomando como referência o projeto Atlas Linguístico do Amapá (ALAP). Esta seção busca mostrar os procedimentos metodológicos adotados para a descrição dos processos 
fonológicos presentes na fala de amapaenses. Serão descritos a seguir a rede de pontos, o perfil do informante, o instrumento de pesquisa e o tratamento dos dados.

Os pontos de inquérito desta pesquisa são os mesmos selecionados para o ALAP. Neste sentido foram consideradas 10 localidades do estado do Amapá, a saber: Macapá (1); Santana (2); Mazagão (3); Laranjal do Jarí (4); Pedra Branca do Amapari (5); Porto Grande (6); Tartarugalzinho (7); Amapá (8); Calçoene (9) e Oiapoque (10).

De acordo com Razky, Ribeiro e Sanches (2017, p. 37), as localidades foram selecionadas a partir dos seguintes critérios: densidade demográfica; distribuição espacial das localidades; importância econômica; e aspecto sociocultural da localidade. Desta forma, 10 dos 16 municípios do estado compuseram a rede de pontos do ALAP.

Assim como as localidades, os informantes selecionados para esta pesquisa também dizem respeito ao grupo de colaboradores do ALAP. Assim, foram controladas as seguintes variáveis, como mostra o quadro 02.

Quadro 02 - Perfil dos informantes

\begin{tabular}{|c|c|c|c|}
\hline Informante & Faixa etária & Sexo & Escolaridade \\
\hline 01 & $18-30$ & Masculino & Fundamental \\
\hline 01 & $18-30$ & Feminino & Fundamental \\
\hline 01 & $50-75$ & Masculino & Fundamental \\
\hline 01 & $50-75$ & Feminino & Fundamental \\
\hline
\end{tabular}

Fonte: Elaboração dos autores.

Para seleção do informante, foram elencados seis critérios, considerados por Razky, Ribeiro e Sanches (2017), como: a) ter nascido no município; b) ser filho de pais nascidos na região; c) não ter morado em outro estado ou região por mais de um terço de sua vida; d) ter nível de instrução escolar variando de analfabeto ao ensino fundamental completo; e) possuir boas condições de saúde e de fonação; e f) ter disponibilidade para a entrevista.

Para a seleção dos itens fonéticos, utilizou-se os dados do projeto ALAP, que foram coletados com base no Questionário FonéticoFonológico (QFF) do projeto ALiB (2001), contendo 159 questões. Para a descrição geossociolinguística dos dados, foram selecionados os seguintes itens fonéticos: assobio, passagem, homem, clara, planta, placa, bicicleta, arroz, três, giz, caspa, paz, prateleira, caixa, tesoura, manteiga, peixe, ouvido, elefante, hóspede e muito. 
V. $10(2)$

$1-23$

maio-ago 2020

Para a organização dos itens, foi consultado o banco de dados do projeto ALAP referente ao Questionário Fonético-Fonológico (QFF), contendo os áudios e as transcrições fonéticas do questionário. De posse dos arquivos, realizou-se um levantamento dos itens fonéticos que poderiam ser utilizados, dentre os 159 itens pertencentes ao QFF, consideraram-se somente 17 deles em virtude de terem sido os itens que mais sofreram modificações fonético-fonológicas, evidenciando assim processos fonológicos de substituição ou transformação.

Após a seleção dos itens, foi feita a apreciação dos áudios juntamente com as transcrições fonéticas disponibilizadas, com o intuito de confirmar e validar os fenômenos fonológicos encontrados. Em seguida, organizaram-se as tabelas e os quadros, contendo a transcrição grafemática e os números de ocorrência para cada processo fonológico.

\section{Descrição geossociolinguística dos resultados}

Nesta seção, busca-se apresentar os resultados encontrados em relação aos processos fonológicos de substituição ou transformação. Assim, foram identificados os seguintes fenômenos: degeneração, desnasalação, ditongação, monotongação, metafonia e nasalação. Os itens fonéticos que apontaram a presença desses fenômenos foram assobio, passagem, homem, arroz, três, giz, caspa, paz, prateleira, caixa, tesoura, manteiga, peixe, ouvido, elefante, hóspede e muito. Abaixo segue o quadro 03 ilustrando o tipo de fenômeno fonológico, o item fonético analisado e seu número de ocorrência.

Quadro 03 - Fenômenos fonológicos investigados

\begin{tabular}{|c|c|c|}
\hline FENÔMENOS & ITEM FONÉTICO & $\begin{array}{c}\mathbf{N}^{\mathbf{0}} \text { de } \\
\text { ocorrências }\end{array}$ \\
\hline Degeneração & assobio > assuvio & 11 \\
\hline \multirow{2}{*}{ Desnasalação } & passagem > passagi & 35 \\
\cline { 2 - 3 } & homem > homi & 22 \\
\hline \multirow{3}{*}{ Ditongação } & arroz > arroiz & 32 \\
\cline { 2 - 3 } & três > treis & 31 \\
\cline { 2 - 3 } & giz > giiz & 34 \\
\cline { 2 - 3 } & caspa > caispa & 29 \\
\cline { 2 - 3 } & paz > paiz & 33 \\
\hline
\end{tabular}




\begin{tabular}{|c|c|c|}
\hline \multirow{4}{*}{ Monotongação } & prateleira > pratelera & 26 \\
\cline { 2 - 3 } & caixa > caxa & 22 \\
\cline { 2 - 3 } & tesoura > tesora & 31 \\
\cline { 2 - 3 } & manteiga > mantega & 30 \\
\cline { 2 - 3 } & peixe > pexi & 31 \\
\cline { 2 - 3 } & ouvido > ovido & 14 \\
\hline \multirow{2}{*}{ Metafonia } & elefante > elefanti & 36 \\
\cline { 2 - 3 } & hóspede > hóspedi & 24 \\
\hline Nasalação & muito > muintu & 28 \\
\hline
\end{tabular}

Fonte: Elaboração dos autores.

A seguir apresenta-se cada fenômeno fonológico com sua respectiva descrição geossociolinguística.

a) degeneração: consiste na transformação do fonema /b/ no fonema /v/. Os dados analisados mostram que esse fenômeno esteve presente no item assobio.

No item assobio > assovio, o fenômeno ocorreu no ponto 1 (Macapá), na fala de dois (2) informantes, da mulher jovem e do homem idoso. No ponto 2 (Santana) houve apenas uma (1) ocorrência na fala do homem idoso. No ponto 3 (Mazagão) não houve ocorrência. No ponto 5 (Pedra Branca) o fenômeno ocorreu somente na fala do homem jovem. No ponto 6 (Porto Grande) houve a presença somente na fala do homem idoso. No ponto 7 (Tartarugalzinho) houve a presença do fenômeno na fala da mulher jovem e do homem idoso. No ponto 8 (Amapá) houve a presença do fenômeno na fala de dois informantes jovens. No ponto 10 (Oiapoque) houve ocorrência na fala da mulher jovem e do homem idoso. Nos pontos 4 (Laranjal do Jarí) e 9 (Calçoene) não houve ocorrência.

No que tange as variáveis sociais, percebe-se que o fator sexo apresenta maior frequência de presença do fenômeno degeneração na fala dos homens, conforme quadro 04 abaixo. 
V. $10(2)$

$1-23$

maio-ago

2020

Quadro 04 - Variáveis sociais para o item assobio

\begin{tabular}{|c|c|c|}
\hline \multicolumn{2}{|c|}{ Variável faixa etária } & \multirow{2}{*}{ Total de ocorrências } \\
\hline Faixa etária I & Faixa etária II & \\
\hline 06 & 05 & \\
Variável sexo & \multirow{2}{*}{$\mathbf{1 1}$} \\
\hline Homem & Mulher & \\
\hline 07 & 04 & \\
\hline \multicolumn{2}{|c|}{07} & \\
\hline
\end{tabular}

Fonte: Elaboração dos autores.

b) desnasalação: consiste na transformação de um fonema nasal em um fonema oral. Os dados analisados mostram que esse fenômeno esteve presente nos itens passagem e homem.

No item passagem > passagi, o fenômeno ocorreu no ponto 4 (Laranjal do Jari) na fala de três (3) informantes, do homem jovem e dos dois informantes idosos. No ponto 6 (Porto Grande) houve a presença do fenômeno apenas na fala dos informantes idosos. No ponto 7 (Tartarugalzinho) houve três (3) ocorrências, na fala dos dois informantes jovens e do homem idoso. No ponto 9 (Calçoene) também houve três (3) ocorrências na fala dos dois informantes jovens e da mulher idosa. Nos pontos 1 (Macapá), 2 (Santana), 3 (Mazagão), 5 (Pedra Branca), 8 (Amapá) e 10 (Oiapoque) houve a presença do fenômeno na fala de todos os informantes.

No que tange às variáveis sociais, percebe-se que entre os fatores faixa etária e sexo não há influência para a presença do fenômeno desnasalação, conforme quadro 05 abaixo.

Quadro 05 - Variáveis sociais para o item passagem

\begin{tabular}{|c|c|c|}
\hline \multicolumn{2}{|c|}{ Variável faixa etária } & \multirow{2}{*}{ Total de ocorrências } \\
\hline Faixa etária I & Faixa etária II & \\
\hline 17 & 18 & \\
\cline { 1 - 1 } Variável sexo & \multirow{3}{*}{35} \\
\cline { 1 - 1 } Homem & Mulher & \\
\hline 18 & 17 & \\
\hline Fonte: Elaboração dos autores.
\end{tabular}

No item homem > homi, o fenômeno esteve presente no ponto 2 (Santana) na fala do homem jovem e da mulher idosa. No ponto 3 (Mazagão) somente o homem jovem produziu o fenômeno, a mulher jovem e o homem idoso não responderam ao questionário. No ponto 5 
(Pedra Branca) o fenômeno ocorreu apenas na fala da mulher jovem. No ponto 6 (Porto Grande) houve a presença somente na fala das mulheres. No ponto 7 (Tartarugalzinho) ocorreu exclusivamente na fala do homem idoso. No ponto 10 (Oiapoque) houve a presença do fenômeno na fala de três (3) informantes, da mulher jovem e dos dois informantes idosos. No ponto 1 (Macapá) não houve ocorrência. Nos pontos 4 (Laranjal do Jarí), 8 (Amapá) e 9 (Calçoene) o fenômeno ocorreu na fala de todos os informantes.

No que diz respeito às variáveis sociais, observa-se que os fatores sexo e idade não apresentam influência para a presença do fenômeno desnasalação na fala dos informantes, conforme quadro 06 abaixo.

Quadro 06 - Variáveis sociais para o item homem

\begin{tabular}{|c|c|c|}
\hline \multicolumn{2}{|c|}{ Variável faixa etária } & \multirow{2}{*}{ Total de ocorrências } \\
\cline { 1 - 2 } Faixa etária I & Faixa etária II & \\
\hline 11 & 11 & \\
\hline \multicolumn{2}{|c|}{ Variável sexo } \\
\cline { 1 - 2 } Homem & Mulher & \multirow{2}{*}{$\mathbf{2 2}$} \\
\hline 10 & 12 & \\
\hline Fonte: Elaboração dos autores.
\end{tabular}

c) ditongação: consiste na transformação de um hiato ou uma vogal em um ditongo. Os dados analisados mostram que esse fenômeno esteve presente nos itens arroz, três, giz, caspa e paz.

No item arroz > arroiz, ofenômeno ocorreu no ponto 3(Mazagão), na fala da mulher jovem. No ponto 4 (Laranjal do Jari) ocorreu na fala dos dois (2) informantes jovens e do homem idoso. No ponto 5 (Pedra Branca) ocorreu somente na fala do homem idoso. No ponto 9 (Calçoene) o fenômeno também ocorreu na fala dos dois informantes jovens e do homem idoso. Nos pontos 1 (Macapá), 2 (Santana), 6 (Porto Grande), 7 (Tartarugalzinho, 8 (Amapá) e 10 (Oiapoque) todos os informantes produziram o fenômeno.

No que diz respeito às variáveis sociais, observa-se que os fatores faixa etária e sexo mostram não influenciar a presença do fenômeno ditongação na fala dos informantes, conforme quadro 07 abaixo. 
V. $10(2)$

$1-23$

maio-ago

2020

Quadro 07 - Variáveis sociais para o item arroz

\begin{tabular}{|c|c|c|}
\hline \multicolumn{2}{|c|}{ Variável faixa etária } & \multirow{2}{*}{ Total de ocorrências } \\
\hline Faixa etária I & Faixa etária II & \\
\hline 17 & 15 & \\
\cline { 1 - 1 } Variável sexo & \multirow{2}{*}{32} \\
\hline Homem & Mulher & \\
\hline 17 & 15 & \\
\hline \multicolumn{2}{|c|}{ Fonte: Elaboração dos autores. }
\end{tabular}

No item três > treis, a presença do fenômeno ocorreu no ponto 3 (Mazagão) na fala do homem idoso. No ponto 4 (Laranjal do Jari) houve a presença de três (3) ocorrências, na fala dos dois (2) informantes jovens e do homem idoso. No ponto 5 (Pedra Branca) também houve a presença de três (3) ocorrências, na fala do homem jovem e dos dois (2) informantes idosos. No ponto 7 (Tartarugalzinho) houve duas (2) ocorrências na fala dos informantes homens. No ponto 9 (Calçoene) houve três (3) ocorrências, na fala dos dois (2) informantes jovens e do homem idoso. No ponto 10 (Oiapoque) também houve a presença de três (3) ocorrências, na fala dos informantes jovens e da mulher idosa. Nos pontos 1 (Macapá), 2 (Santana), 6 (Porto Grande) e 8 (Amapá) todos os informantes produziram o fenômeno.

No que diz respeito às variáveis sociais, observa-se que os fatores faixa etária e sexo não influenciam a presença do fenômeno ditongação na fala dos informantes, conforme quadro 08 abaixo.

Quadro 08 - Variáveis sociais para o item três

\begin{tabular}{|c|c|c|}
\hline \multicolumn{2}{|c|}{ Variável faixa etária } & \multirow[t]{2}{*}{ Total de ocorrências } \\
\hline Faixa etária I & Faixa etária II & \\
\hline 16 & 15 & \multirow{4}{*}{31} \\
\hline \multicolumn{2}{|c|}{ Variável sexo } & \\
\hline Homem & Mulher & \\
\hline 16 & 15 & \\
\hline
\end{tabular}

No item giz > giiz, o fenômeno esteve presente no ponto 2 (Santana) na fala do homem jovem e também nos dois (2) informantes idosos. No ponto 3 (Mazagão) houve a presença na fala dos dois (2) informantes jovens e do homem idoso. No ponto 5 (Pedra Branca) houve a presença do fenômeno somente na fala das duas (2) mulheres. No ponto 9 (Calçoene) houve a presença na fala do homem jovem e na fala dos dois (2) informantes idosos. No ponto 10 (Oiapoque) 
houve a presença na fala dos dois (2) informantes jovens e da mulher idosa. Nos pontos 1 (Macapá), 4 (Laranjal do Jari), 6 (Porto Grande), 7 (Tartarugalzinho) e 8 (Amapá) houve a presença do fenômeno na fala de todos os informantes.

No que diz respeito às variáveis sociais, observa-se que o fator sexo apresenta uma maior frequência de presença de ditongação na fala dos informantes homens, conforme quadro 09.

Quadro 09 - Variáveis sociais para o item giz

\begin{tabular}{|c|c|c|}
\hline \multicolumn{2}{|c|}{ Variável faixa etária } & \multirow{2}{*}{ Total de ocorrências } \\
\hline Faixa etária I & Faixa etária II & \\
\hline 17 & 17 & \\
\hline \multicolumn{2}{|c|}{ Variável sexo } & \multirow{3}{*}{34} \\
\hline Homem & Mulher & \\
\hline 19 & 15 & \\
\hline Fonte: Elaboração dos autores.
\end{tabular}

No item caspa > caispa houve a presença do fenômeno no ponto 2 (Santana) na fala dos informantes jovens. No ponto 3 (Mazagão) não houve ocorrências. No ponto 5 (Pedra Branca) o fenômeno ocorreu na fala de três (3) informantes, na do homem jovem e na dos dois (2) informantes idosos. No ponto 7 (Tartarugalzinho) houve presença apenas na fala da mulher jovem. No ponto 8 (Amapá) houve três (3) ocorrências, na fala da mulher jovem e dos dois (2) informantes idosos. Nos pontos 1 (Macapá), 4 (Tartarugalzinho), 6 (Porto Grande), 9 (Calçoene) e 10 (Oiapoque) o fenômeno ocorreu na fala de todos os informantes.

No que diz respeito às variáveis sociais, observa-se que, entre os fatores faixa etária e sexo, não há tendência para a presença do fenômeno ditongação na fala dos informantes, conforme quadro 10.

Quadro 10 - Variáveis sociais para o item caspa

\begin{tabular}{|c|c|c|}
\hline \multicolumn{2}{|c|}{ Variável faixa etária } & \multirow{2}{*}{ Total de ocorrências } \\
\hline Faixa etária I & Faixa etária II & \\
\hline 15 & 14 & \\
\hline \multicolumn{2}{|c|}{ Variável sexo } & \multirow{2}{*}{$\mathbf{2 9}$} \\
\hline Homem & Mulher & \\
\hline 14 & 15 & \\
\hline Fonte: Elaboração dos autores.
\end{tabular}


V. $10(2)$

$1-23$

maio-ago

2020

No item paz > paiz houve a presença do fenômeno no ponto 3 (Mazagão), na fala da mulher jovem e dos dois (2) informantes idosos. No ponto 4 (Laranjal do Jari) houve a presença na fala dos dois (2) informantes jovens e do homem idoso. No ponto 5 (Pedra Branca) apenas as duas (2) informantes mulheres realizaram o fenômeno. No ponto 7 (Tartarugalzinho) apenas os dois (2) homens realizaram o fenômeno. No ponto 9 (Calçoene) houve a presença de três (3) ocorrências, na fala dos dois (2) informantes jovens e do homem idoso. Nos pontos 1 (Macapá), 2 (Santana), 6 (Porto Grande), 8 (Amapá) e 10 (Oiapoque) o fenômeno ocorreu na fala de todos os informantes.

No que tange às variáveis sociais, observa-se que, entre os fatores faixa etária e sexo, não há uma frequência alta de presença do fenômeno ditongação na fala dos informantes, conforme quadro 11.

Quadro 11 - Variáveis sociais para o item paz

\begin{tabular}{|c|c|c|}
\hline \multicolumn{2}{|c|}{ Variável faixa etária } & \multirow{2}{*}{ Total de ocorrências } \\
\hline Faixa etária I & Faixa etária II & \\
\hline 17 & 16 & \\
\hline \multicolumn{2}{|c|}{ Variável sexo } & \multirow{2}{*}{33} \\
\hline Homem & Mulher & \\
\hline 17 & 16 & \\
\hline \multicolumn{2}{|c|}{ Fonte: Elaboração dos autores. }
\end{tabular}

d) monotongação: consiste na transformação de um ditongo em uma vogal. Os dados analisados mostram que esse fenômeno esteve presente nos itens prateleira, caixa, tesoura, manteiga, peixe e ouvido.

No item prateleira > pratelera, no ponto 1 (Macapá) houve a presença do fenômeno na fala dos dois (2) informantes jovens e do homem idoso. No ponto 2 (Santana) os dois (2) informantes da segunda faixa etária produziram o fenômeno. No ponto 3 (Mazagão) não houve ocorrências. No ponto 5 (Pedra Branca) o fenômeno ocorreu na fala de três (3) informantes, na do homem jovem e na fala dos dois (2) informantes idosos. No ponto 6 (Porto Grande) houve a presença na fala de três (3) informantes, dois (2) informantes jovens e uma mulher idosa. No ponto 7 (Tartarugalzinho) só houve presença na fala do homem jovem. No ponto 9 (Calçoene) os dois (2) informantes jovens produziram o fenômeno. Nos pontos 4 (Laranjal do Jarí), 8 (Amapá) e 10 (Oiapoque) houve a presença do fenômeno na fala de todos os informantes. 
No que tange às variáveis sociais, percebe-se que os fatores faixa etária e sexo apresentam uma leve tendência para a presença do fenômeno monotongação na fala dos informantes jovens e na dos homens, conforme o quadro 12 abaixo.

Quadro 12 - Variáveis sociais para o item prateleira

\begin{tabular}{|c|c|c|}
\hline \multicolumn{2}{|c|}{ Variável faixa etária } & \multirow{2}{*}{ Total de ocorrências } \\
\hline Faixa etária I & Faixa etária II & \\
\hline 14 & 12 & \\
\hline \multicolumn{2}{|c|}{ Variável sexo } & \multirow{2}{*}{$\mathbf{2 6}$} \\
\hline Homem & Mulher & \\
\hline 14 & 12 & \\
\hline \multicolumn{2}{|c|}{ Fonte: Elaboração dos autores. }
\end{tabular}

No item caixa > caxa houve a presença do fenômeno no ponto 1 (Macapá) na fala dos dois (2) informantes idosos. No ponto 2 (Santana) houve apenas uma (1) ocorrência na fala da mulher idosa. No ponto 3 (Mazagão) houve a presença de duas (2) ocorrências, nos dois (2) informantes idosos. No ponto 5 (Pedra Branca) o fenômeno ocorreu somente na fala da mulher idosa. No ponto 6 (Porto Grande) houve a presença na fala dos dois (2) informantes jovens. No ponto 7 (Tartarugalzinho) houve a presença na fala do homem jovem e da mulher idosa. No ponto 8 (Amapá) houve a presença do fenômeno na fala da mulher jovem e do homem idoso. No ponto 10 (Oiapoque) também houve presença na fala da mulher jovem e do homem idoso. Nos pontos 4 (Laranjal do Jarí) e 9 (Calçoene) houve a presença do fenômeno na fala de todos os informantes.

No que diz respeito às variáveis sociais, percebe-se que o fator sexo possui uma maior frequência para a presença do fenômeno de monotongação na fala das mulheres, já a variável faixa etária se destaca mostrando maior frequência em informantes idosos, conforme quadro 13.

Quadro 13 - Variáveis sociais para o item caixa

\begin{tabular}{|c|c|c|}
\hline \multicolumn{2}{|c|}{ Variável faixa etária } & \multirow{2}{*}{ Total de ocorrências } \\
\hline Faixa etária I & Faixa etária II & \\
\hline 09 & 13 & \\
\hline \multicolumn{2}{|c|}{ Variável sexo } & \multirow{2}{*}{$\mathbf{2 2}$} \\
\hline Homem & Mulher & \\
\hline 10 & 12 & \\
\hline Fonte: Elaboração dos autores.
\end{tabular}


V. $10(2)$

$1-23$

maio-ago

2020

No item tesoura > tesora o fenômeno ocorreu no ponto 1 (Macapá) somente na fala da mulher idosa. No ponto 2 (Santana) houve a presença do fenômeno na fala dos dois (2) informantes jovens. No ponto 4 (Laranjal do Jari) houve três (3) ocorrências, na fala dos dois (2) informantes jovens e do homem idoso. No ponto 5 (Pedra Branca) houve a presença do fenômeno somente na fala das duas (2) mulheres. No ponto 7 (Tartarugalzinho) também houve três (3) ocorrências, na fala do homem jovem e na fala de dois (2) informantes idosos. Nos pontos 3 (Mazagão), 6 (Porto Grande), 8 (Amapá), 9 (Calçoene) e 10 (Oiapoque) o fenômeno ocorreu na fala de todos os informantes.

No que diz respeito às variáveis sociais, observa-se que entre os fatores faixa etária e sexo não há influência para a presença do fenômeno monotongação, conforme quadro 14.

Quadro 14 - Variáveis sociais para o item tesoura

\begin{tabular}{|c|c|c|}
\hline \multicolumn{2}{|c|}{ Variável faixa etária } & \multirow{2}{*}{ Total de ocorrências } \\
\hline Faixa etária I & Faixa etária II & \\
\hline 16 & 15 & \\
\cline { 1 - 2 } Variável sexo & \multirow{3}{*}{3} \\
\cline { 1 - 1 } Homem & Mulher & \\
\hline 15 & 16 & \\
\hline Fonte: Elaboração dos autores.
\end{tabular}

No item manteiga > mantega, o fenômeno foi registrado no ponto 2 (Santana) na fala do homem jovem e na fala dos dois (2) informantes idosos. No ponto 3 (Mazagão) o fenômeno ocorreu somente na fala das duas (2) mulheres. No ponto 5 (Pedra Branca) o fenômeno ocorreu na fala de três (3) informantes, na dos dois (2) informantes jovens e do homem idoso. No ponto 6 (Porto Grande) houve a presença somente na fala das duas (2) mulheres. No ponto 7 (Tartarugalzinho) só houve presença na fala da mulher idosa, a mulher jovem não respondeu ao questionário. No ponto 9 (Calçoene) houve a presença de três (3) ocorrências, na fala do homem jovem e dos dois (2) informantes idosos. Nos pontos 1 (Macapá), 4 (Laranjal do Jarí), 8 (Amapá) e 10 (Oiapoque) houve a presença do fenômeno na fala de todos os informantes.

No que tange às variáveis sociais, observa-se que os fatores faixa etária e sexo não influenciam a presença do fenômeno monotongação, conforme quadro 15. 
Quadro 15 - Variáveis sociais para o item manteiga

\begin{tabular}{|c|c|c|}
\hline \multicolumn{2}{|c|}{ Variável faixa etária } & \multirow{2}{*}{ Total de ocorrências } \\
\hline Faixa etária I & Faixa etária II & \\
\hline 14 & 16 & \\
\hline \multicolumn{2}{|c|}{ Variável sexo } & \multirow{2}{*}{30} \\
\hline Homem & Mulher & \\
\hline 14 & 16 & \\
\hline
\end{tabular}

No item peixe $>$ pexi houve a presença no ponto 2 (Santana) na fala do homem jovem e dos dois (2) informantes idosos. No ponto 3 (Mazagão) houve a presença na fala da mulher jovem e dos dois (2) informantes idosos. No ponto 4 (Laranjal do Jarí) somente os informantes jovens realizaram o fenômeno. No ponto 5 (Pedra Branca) houve três (3) ocorrências, na fala dos informantes jovens e do homem idoso. No ponto 6 (Porto Grande) também houve três (3) ocorrências na fala do homem jovem e dos dois (2) informantes idosos. No ponto 7 (Tartarugalzinho) apenas as duas (2) mulheres realizaram o fenômeno. No ponto 8 (Amapá) houve três (3) ocorrências, na fala da mulher jovem e dos dois (2) informantes idosos. Nos pontos 1 (Macapá), 9 (Calçoene) e 10 (Oiapoque) houve a presença do fenômeno na fala de todos os informantes.

No que tange às variáveis sociais, observa-se que o fator sexo apresenta uma maior frequência para a presença do fenômeno monotongação na fala dos homens, conforme quadro 16.

Quadro 16 - Variáveis sociais para o item peixe

\begin{tabular}{|c|c|c|}
\hline \multicolumn{2}{|c|}{ Variável faixa etária } & \multirow{2}{*}{ Total de ocorrências } \\
\hline Faixa etária I & Faixa etária II & \\
\hline 15 & 16 & \\
\hline \multicolumn{2}{|c|}{ Variável sexo } & \multirow{3}{*}{$\mathbf{3 1}$} \\
\hline Homem & Mulher & \\
\hline 17 & 14 & \\
\hline \multicolumn{2}{|c|}{ Fonte: Elaboração dos autores. }
\end{tabular}

No item ouvido > ovido houve três (3) ocorrências no ponto 4 (Laranjal do Jari) na fala dos dois (2) informantes jovens e da mulher idosa. No ponto 5 (Pedra Branca do Amapari) não houve ocorrências. No ponto 6 (Porto Grande) houve a presença na fala de três (3) informantes, dos dois (2) informantes jovens e do homem idoso. No ponto 7 (Tartarugalzinho) não houve ocorrências, a mulher jovem 
V. $10(2)$

$1-23$

maio-ago 2020

não respondeu ao questionário. No ponto 8 (Amapá) houve a presença do fenômeno na fala das duas (2) mulheres. No ponto 9 (Calçoene) houve a presença na fala dos dois (2) informantes jovens e do homem idoso. No ponto 10 (Oiapoque) também houve a presença na fala dos dois informantes jovens e do homem idoso. Nos pontos 1 (Macapá), 2 (Santana) e 3 (Mazagão) não houve a presença do fenômeno na fala dos informantes.

A respeito das variáveis sociais, percebe-se que o fator faixa etária possui maior frequência de presença do fenômeno monotongação nos informantes jovens, conforme quadro 17.

Quadro 17 - Variáveis sociais para o item ouvido

\begin{tabular}{|c|c|c|}
\hline \multicolumn{2}{|c|}{ Variável faixa etária } & \multirow{2}{*}{ Total de ocorrências } \\
\hline Faixa etária I & Faixa etária II & \\
\hline 09 & 05 & \\
\hline \multicolumn{2}{|c|}{ Variável sexo } & \multirow{2}{*}{$\mathbf{1}$} \\
\cline { 1 - 1 } Homem & Mulher & \\
\hline 07 & 07 & \\
\hline Fonte: Elaboração dos autores.
\end{tabular}

e) metafonia: consiste na alteração de timbre ou altura de uma vogal. Os dados analisados mostram que esse fenômeno esteve presente nos itens elefante e hóspede.

No item elefante > elefanti houve a presença do fenômeno no ponto 3 (Mazagão), os dois (2) informantes jovens e o homem idoso realizaram o fenômeno, a mulher idosa não respondeu ao questionário. No ponto 5 (Pedra Branca) as duas (2) mulheres realizaram o fenômeno, os dois (2) homens não responderam ao questionário. No ponto 9 (Calçoene) os dois (2) informantes jovens e o homem idoso realizaram o fenômeno, a mulher idosa não respondeu ao questionário. Nos pontos 1 (Macapá), 2 (Santana), 4 (Laranjal do Jari), 6 (Porto Grande), 7 (Tartarugalzinho), 8 (Amapá) e 10 (Oiapoque) houve a presença do fenômeno na fala de todos os informantes.

Para as variáveis sociais, percebe-se que o fator faixa etária teve uma maior frequência de presença do fenômeno metafonia nos informantes jovens, conforme quadro 18. 
Quadro 18 - Variáveis sociais para o item elefante

\begin{tabular}{|c|c|c|}
\hline \multicolumn{2}{|c|}{ Variável faixa etária } & \multirow[t]{2}{*}{ Total de ocorrências } \\
\hline Faixa etária I & Faixa etária II & \\
\hline 19 & 17 & \multirow{4}{*}{36} \\
\hline \multicolumn{2}{|c|}{ Variável sexo } & \\
\hline Homem & Mulher & \\
\hline 18 & 18 & \\
\hline
\end{tabular}

No item hóspede > hóspedi, houve a presença do fenômeno no ponto 2 (Santana), na qual apenas os informantes jovens realizaram o fenômeno, já os idosos não responderam ao questionário. No ponto 3 (Mazagão) somente os informantes jovens realizaram o fenômeno e os idosos também não responderam ao questionário. No ponto 4 (Laranjal do Jarí) houve somente uma (1) ocorrência na fala do homem idoso, a mulher idosa não respondeu ao questionário. No ponto 5 (Pedra Branca) o fenômeno ocorreu na fala de dois (2) informantes, na do homem jovem e na da mulher idosa, o homem idoso não respondeu ao questionário. No ponto 6 (Porto Grande) houve a presença na fala de três (3) informantes, na dos dois (2) informantes jovens e do homem idoso, a mulher idosa não respondeu ao questionário. No ponto 7 (Tartarugalzinho) houve presença somente na fala dos dois (2) jovens. No ponto 8 (Amapá) houve a presença na fala de três (3) informantes, na do homem jovem e dos dois (2) idosos. No ponto 9 (Calçoene) as duas (2) mulheres produziram o fenômeno, os dois (2) homens não responderam ao questionário. No ponto 10 (Oiapoque) o fenômeno ocorreu somente na fala dos dois (2) jovens, o homem idoso não respondeu ao questionário. No ponto 1 (Macapá) todos realizaram o fenômeno.

Sobre as variáveis sociais, observa-se que o fator faixa etária pode influenciar a presença do fenômeno metafonia na fala dos jovens, conforme quadro 19.

Quadro 19 - Variáveis sociais para o item hóspede

\begin{tabular}{|c|c|c|}
\hline \multicolumn{2}{|c|}{ Variável faixa etária } & \multirow{2}{*}{ Total de ocorrências } \\
\hline Faixa etária I & Faixa etária II & \\
\hline 15 & 09 & \\
\hline \multicolumn{2}{|c|}{ Variável sexo } & \\
\hline Homem & Mulher & \\
\hline 12 & 12 & \\
\hline Fonte: Elaboração dos autores.
\end{tabular}


V. $10(2)$

$1-23$

maio-ago

2020

f) nasalação: consiste na transformação de um fonema oral em fonema nasal como em até > inté; aipim > aimpim; igual > ingual etc. Os dados analisados aqui mostram que esse fenômeno esteve presente no item muito.

No item muito > muito o fenômeno ocorreu no ponto 1 (Macapá) na fala das duas (2) mulheres, o homem idoso não respondeu ao questionário. No ponto 4 (Laranjal do Jarí) houve apenas ocorrências na fala das duas (2) mulheres. No ponto 6 (Porto Grande) houve a presença na fala do homem jovem e da mulher idosa. No ponto 7 (Tartarugalzinho) houve três (3) ocorrências na fala dos dois (2) informantes jovens e da mulher idosa. No ponto 8 (Amapá) houve a presença na fala do homem jovem e da mulher idosa. No ponto 9 (Calçoene) houve ocorrência na fala das duas (2) mulheres. No ponto 10 (Oiapoque) o fenômeno ocorreu na fala de três (3) informantes, da mulher jovem e dos dois (2) idosos. Nos pontos 2 (Santana), 3 (Mazagão) e no ponto 5 (Pedra Branca) houve a presença do fenômeno na fala de todos os informantes.

No que tange às variáveis sociais, percebe-se que o fator sexo pode influenciar a presença do fenômeno nasalação na fala das mulheres, conforme quadro 20.

Quadro 20 - Variáveis sociais para o item muito

\begin{tabular}{|c|c|c|}
\hline \multicolumn{2}{|c|}{ Variável faixa etária } & \multirow{2}{*}{ Total de ocorrências } \\
\hline Faixa etária I & Faixa etária II & \\
\hline 14 & 14 & \\
\cline { 1 - 1 } Variável sexo & \multirow{2}{*}{$\mathbf{2}$} \\
\hline Homem & Mulher & \\
\hline 10 & 18 & \\
\hline Fonte: Elaboração dos autores.
\end{tabular}

Dentre os resultados acima descritos, pode-se notar que os fenômenos desnasalação e metafonia caracterizam maior frequência de realização dos processos de substituição ou transformação, pois os itens analisados chegam a quase 100\% de ocorrência.

Em relação às variáveis sociais, observa-se que entre os fatores sexo e faixa etária há maior frequência de realização do fenômeno na fala dos homens, como em: degeneração (assovio), ditongação (giiz) e monotongação (pratelera e pexe); e essa frequência também ocorre na fala dos jovens, como em: monotongação (pratelera e ovido) e metafonia (elefanti e hóspedi). 
Houve também fenômenos nos quais os fatores sociais não apresentaram diferença significativa para qualquer que fosse a variável (sexo ou faixa etária), como foi o caso de desnasalação (passagi), ditongação (trêis, caispa e paiz) e monotongação (tesora e mantega).

Do ponto de vista geográfico, a maior concentração de ocorrências se deu em municípios localizados mais ao norte do estado, como em Tartarugalzinho, Amapá, Calçoene e Oiapoque. Isso nos faz levantar a hipótese de que quanto mais distante o falante estiver da área urbana (Macapá, capital do estado), maior será a realização dos processos fonológicos.

Com base na descrição geossociolinguística feita acima, é importante buscar explicações para entender como ocorrem esses processos fonológicos e apontar quais os fatores históricos e linguísticos estão envolvidos nesses processos.

Em busca dessas respostas, Botelho e Leite (2005), numa explicação diacrônica da língua, afirmam que muitos vocábulos que já estão fixados na língua portuguesa sofreram transformações ao longo tempo, sobretudo na passagem do latim para o português. E que nesse movimento evolutivo da língua outros vocábulos continuam transformando-se.

Já numa explicação sincrônica da língua, Cagliari (2002) e Othero (2005) defendem a ideia de que os processos fonológicos são inatos, naturais e universais, uma vez que as línguas naturais se organizam em sistemas fonológicos regidos por princípios comuns. Esses processos abarcam numerosas mudanças que atuam sobre a estrutura da sílaba que podem derivar a partir das necessidades e dificuldades articulatórias e perceptuais do falante, resultando, assim, em adaptações fonológicas dos padrões da fala restritas à capacidade humana.

\section{Considerações finais}

O objetivo principal deste trabalho foi identificar os tipos de processos fonológicos existentes no português brasileiro falado no Amapá, tendo como suporte os dados sonoros do projeto Atlas Linguístico do Amapá (ALAP). Logo, o objetivo foi alcançado por meio da descrição geossociolinguística dos itens fonéticos selecionados.

Diante disso, constatou-se que os processos de transformação ou substituição podem sofrer influências de variáveis sociais e/ou 
V. $10(2)$

$1-23$

maio-ago

2020

geográficas. Verificou-se também que os itens fonéticos analisados possuem maior frequência para a presença do fenômeno na fala dos informantes homens (variável sexo), na dos jovens (variável faixa etária) e em municípios localizados mais ao norte do Amapá (variável geográfica).

Este estudo, apesar de não dar conta de todos os itens fonéticos do QFF aplicado pelo projeto ALAP, nos proporcionou identificar, de antemão, como os processos de transformação ou substituição do português estão se fixando no falar amapaense. Para que possamos obter uma visão mais ampla desses processos, faz-se necessária uma investigação comparativa com outros dados coletados de mesma natureza para que assim seja possível traçar um perfil dos processos fonológicos presentes no português falado na Amazônia.

\section{Referências}

BISOL, L. (Org.). Introdução aos estudos da fonologia do português brasileiro. 4. ed. Porto Alegre: EDIPUCRS, 2005.

BOTELHO, J. M.; LEITE, I. L. Metaplasmos contemporâneos: um estudo acerca das atuais transformações fonéticas da Língua Portuguesa. In: Congresso de Letras da UERJ, 2., 2005, São Gonçalo. Anais do II CLUERJ-SG. São Gonçalo: UERJ, 2005. p. 1-12.

CARDOSO, S. Geolinguística: tradição e modernidade. São Paulo: Parábola Editorial, 2010.

CAGLIARI, L. C. Análise fonológica: introdução à teoria e prática, com destaque para o modelo fonêmico. Campinas, SP: Mercado de Letras, 2002.

FERREIRA, C.; CARDOSO, S. A dialetologia no Brasil. São Paulo: Contexto, 1994.

GUEDES, R. J. C. Estudo geossociolinguístico da variação lexical na zona rural do estado do Pará. 2012. Dissertação (Mestrado em Letras) - Programa de Pós-Graduação em Letras - PPGL, Universidade Federal do Pará, Belém, 2012.

LAMPRECHT, R. R. et al. Aquisição fonológica do português: perfil de desenvolvimento e subsídios para terapia. Porto Alegre: Artmed, 2004.

MOLLICA, M. C.; BRAGA, M. L. (Orgs.). Introdução à sociolinguística: o tratamento da variação. 4. ed. rev. São Paulo: Contexto, 2017.

OTHERO, G. de Á. Processos fonológicos na aquisição da linguagem pela criança. ReVEL, Paraná, v. 3, n. 5, p. 1-13, 2005.

RAZKY, A. A dimensão sociodialetal do léxico no Projeto Atlas Linguístico do Brasil. Signum: estudos linguísticos, Londrina, n. 16/2, p. 247-270, dez. 2013. 
RAZKY, A. Pour une approche géo-sociolinguistique de la variation phonétique. Lenguaje (Universidad del Valle), Colômbia, v. 38, n. 2, p. 313-330, 2010.

RAZKY, A; RIBEIRO, C. M. R; SANCHES, R. Atlas Linguístico do Amapá. São Paulo: Labrador, 2017.

SANCHES, R. Gambá ou mucura? Como falam os amapaenses. In: RAZKY, A.; LIMA, A.; OLIVEIRA, M.; SALVADOR, C.; SANCHES, R. (Org.). Variação e diversidade linguística. 1. ed. Belém: UFPA/Faculdade de Letras, 2019. v. 1. p. $19-28$.

SILVA, F. M. Processos fonológicos segmentais na Língua Portuguesa. Revista Littera Online, São Luís, v. 2, n. 4, p. 72-88, 2011.

SILVA, T. C. Fonética e fonologia do português: roteiro de estudos e guia de exercícios. 10. ed. São Paulo: Contexto, 2015.

STAMPE, D. A dissertation on natural phonology. 1973. Tese (Doutorado em Linguística), Programa de Humanidades e Artes, Universidade de Chicago, EUA, 1973.

YAVAS, M.; HERNANDORENA, C. L. M.; LAMPRECHT, R. R. Avaliação fonológica da criança. Porto Alegre: Artes Médicas, 1991. 